\title{
Effect of oral administration of soy-derived phosphatidic acid on concentrations of phosphatidic acid and lyso-phosphatidic acid molecular species in human plasma
}

\author{
Martin Purpura ${ }^{1 *}$, Ralf Jäger ${ }^{1}$, Jordan M Joy², Ryan P Lowery², Jeff D Moore ${ }^{3}$, Jacob M Wilson² \\ From International Society of Sports Nutrition: 10th Annual ISSN Conference and Expo \\ Colorado Springs, CO, USA. 14-15 June 2013
}

\section{Background}

The glycerophospholipid Phosphatidic acid (PA) has been identified as a potential nutritional treatment for gastrointestinal disorders. Dietary food sources rich in PA include cabbage and radish leaves as well as Mallotus japonicas, a Japanese edible herb historically used for the treatment of stomach ulcers. The mammalian target of rapamycin (mTOR) has been shown to regulate rates of muscle protein synthesis and a mechanical stimulus (resistance exercise) has been shown to activate mTOR with PA playing a key role. Supplementation with soy-derived PA significantly increases responses in skeletal muscle hypertrophy, lean body mass, and maximal strength to resistance exercise. PA accounts for less than $0.1 \%$ of the total glycerophospholipid concentration of $201 \mathrm{mg} / \mathrm{dl}$ in the human plasma. 15 of the more than 600 distinct molecular lipid species quantified in human plasma are PA, 6 are lysophosphatidic acid (LPA). Orally administered PA can be metabolized to LPA and glycerophosphate by pancreatic phospholipases A1 and A2, which hydrolyze the fatty acid at the sn- 1 position and the sn- 2 position, respectively. Lysophospholipids are absorbed by the mucosal cells of the gastrointestinal tract and are rapidly re-acylated with fatty acids of the body pool resulting in a newly-formed phospholipid-molecule whose fatty acid composition is determined by the physiological and nutritional status and not by its source. This study sought to assess the effect of soy-derived PA supplementation on concentrations LPA and PA molecular species in human plasma.

\footnotetext{
* Correspondence: martin.purpura@increnovo.com

'Increnovo LLC, 2138 E Lafayette PI, Milwaukee, WI; USA

Full list of author information is available at the end of the article
}

\section{Methods}

After a 12 hour overnight fast one subject (20 years of age, bodyweight of $82 \mathrm{~kg}$, and height of $178 \mathrm{~cm}$ ) was assigned to receive 1.5 grams of soy-derived PA (Mediator, Chemi Nutra, White Bear Lake, MN). Blood draws were taken immediately prior to, and at $30 \mathrm{~min}, 1,2$, 3, and 7 hours following supplementation. The samples were analyzed by an ultra-performance liquid chromatograph with triple quadrupole mass spectrometry (LC/MS/MS) using 17:1-LPA and 37:4-PA as internal standards to determine the concentration of LPA and PA molecular species in human plasma.

\section{Results}

At baseline, 19 PA (highest concentrations: C34:2 (15\%), C40:4 (11\%), and C36:4 (10\%)) and 5 LPA (16:0 (45\%), 18:2 (19\%), 20:4 (17\%), 14:0 (11\%) and 18:1 (8\%)) molecular species could be quantified with total concentrations of PA of $2.66 \mathrm{nmol} / \mathrm{ml}$, and LPA of $0.11 \mathrm{nmol} / \mathrm{ml}$. Plasma concentrations of PA peaked at 3 hours $(+32 \%)$ after ingestion and stayed elevated even after 7 hours $(+18 \%)$. LPA showed a bimodal absorption kinetic with peaks after 1 hour $(+500 \%)$ and 3 hours $(+264 \%)$, after almost dropping back to baseline levels after 2 hours. On an individual fatty acid level, most prominent was a 23-fold increase in 20:4-LPA after 1 hour compared to baseline. The increase in 20:4-LPA does not result from the administration of PA, since soy-derived PA does not contain any arachidonic acid (fatty acids distribution of soy-PA: 18:2 (66.1\%), 18:1 (12.6\%), 16:0 (11.7\%), 18:3 (6.1\%) and 18:0 (3.4\%)). Absorption of soy-derived PA must yield glycerophosphate which is re-acylated with arachidonic acid. 


\section{Conclusion}

LPA and PA can be molecularly identified and measured. LPA, PA and LPA+PA plasma levels increase $30 \mathrm{~min}$ after ingestions, plateau at 1-3 hours and remain above baseline levels after 7 hours. This is the first case study showing that orally administered PA is bioavailable. Future research should repeat this case study with a larger n-size and include the analysis of omega 3 fatty acid-LPA molecular species.

\section{Acknowledgements}

Supported by Chemi Nutra, White Bear Lake, MN.

\section{Authors' details}

${ }^{1}$ Increnovo LLC, 2138 E Lafayette PI, Milwaukee, WI; USA. ${ }^{2}$ Department of Health Sciences and Human Performance, The University of Tampa, Tampa, FL; USA. ${ }^{3}$ Avanti Polar Lipids, Inc., 700 Industrial Park Drive, Alabaster, AL, USA.

Published: 6 December 2013

doi:10.1186/1550-2783-10-S1-P22

Cite this article as: Purpura et al:: Effect of oral administration of soyderived phosphatidic acid on concentrations of phosphatidic acid and lyso-phosphatidic acid molecular species in human plasma. Journal of the International Society of Sports Nutrition 2013 10(Suppl 1):P22.

Submit your next manuscript to BioMed Central and take full advantage of:

- Convenient online submission

- Thorough peer review

- No space constraints or color figure charges

- Immediate publication on acceptance

- Inclusion in PubMed, CAS, Scopus and Google Scholar

- Research which is freely available for redistribution

Submit your manuscript at www.biomedcentral.com/submit 